\title{
The adoption and use of through-life engineering services within UK manufacturing organisations
}

Proc IMechE Part B:

$J$ Engineering Manufacture

2015, Vol. 229(10) 1848-1866

(c) IMechE 2014

Reprints and permissions:

sagepub.co.uk/journalsPermissions.nav DOI: 10.1 I77/09544054|453993 |

pib.sagepub.com

(SAGE

\author{
LE Redding, A Tiwari, R Roy, P Phillips and A Shaw
}

\begin{abstract}
Manufacturing organisations seek ever more innovative approaches in order to maintain and improve their competitive position within the global market. One such initiative that is gaining significance is 'through-life engineering services'. These seek to adopt 'whole life' service support through the greater understanding of component and system performance driven by knowledge gained from maintenance, repair and overhaul activities. This research presents the findings of exploratory research based on a survey of UK manufacturers who provide through-life engineering services. The survey findings illustrate significant issues to be addressed within the field before the concept becomes widely accepted. These include a more proactive approach to maintenance activities based on real-time responses; standardisation of data content, structure, collection, storage and retrieval protocols in support of maintenance; the development of clear definitions, ontologies and a taxonomy of through-life engineering services in support of the service delivery system; lack of understanding of component and system performance due to the presence of 'No Fault Found' events that skew maintenance metrics and the increased use of radio-frequency identification technology in support of maintenance data acquisition.
\end{abstract}

\author{
Keywords \\ Through-life engineering services, maintenance, repair and overhaul, service knowledge feedback
}

Date received: 29 October 2013; accepted: 27 May 2014

\section{Introduction}

As manufacturing organisations seek to sustain and increase their competitive position, the old mantra of quality, cost and delivery is relegated to the role of 'order qualifier ${ }^{1,2}$ with new initiatives being developed and adopted. Two such initiatives are product service systems $(\mathrm{PSS})^{3-7}$ and servitisation. ${ }^{8-11}$ PSS originally evolved as a response to environmental concerns and pressure on limited resources, but the benefits of adoption can improve competitive position. Servitisation is viewed as the process of moving from the position of pure manufacturer to that of service provider. Both these initiatives promote manufacturing organisations moving to increased levels of service offering in support of their products. Typical examples of this transition are found in the offerings of Rolls Royce and GE who manufacture aero-engines and offer availability contracting. This evolution is also observed within many market leaders (typically, MAN Trucks (cab monitoring systems), Bombardier Transportation (Orbita system), Xerox (service-based business model), John Deere (monitoring systems) and Caterpillar (monitoring systems)), all of who employ remote monitoring systems and product degradation knowledge in support of PSS type business models. This is well documented in the literature with industrial product service system (IPS ${ }^{2}$ ) now emerging. ${ }^{12,13}$ IPS $^{2}$ solutions are customised applications that integrate products, services and software to deliver required defined added value that goes beyond pure functionality within an industrial background. Key elements that make such solutions distinct from PSS are the use of technology and software and its focus on the industrial sector.

The key to the success of these initiatives is the increased understanding of product performance,

EPSRC Centre for Innovative Manufacturing, Through-life Engineering Services, Cranfield University, Bedfordshire, UK

\section{Corresponding author:}

LE Redding, EPSRC Centre for Innovative Manufacturing, Through-life Engineering Services, Building 30, Main Campus, Cranfield University, Bedfordshire MK43 OAL, UK.

Email: I.e.redding@cranfield.ac.uk 
component, system and subsystem degradation, diagnostics, prognostics and assessment of the product's availability and remaining useful life (RUL). As companies obtain revenues based on product availability rather than single 'make and purchase' transactions, ${ }^{10,14}$ there emerges an ever-increasing transfer of risk to their revenue due to risk of product failure. With this business model, the manufacturer retains various levels of ownership of the product throughout its life, gaining revenues through increasing levels of service support (servitisation) and is ultimately responsible for end-of-life disposal. Underpinning this is the product support structure and infrastructure by way of the service delivery system which may be internal and/or external to the organisation.

The literature documents many elements of the whole life service delivery system in support of manufactured products. Understanding the current and future performance of the product by harvesting data from sensors while the product is 'in use' is reported in the condition-based monitoring $\left(\mathrm{CBM}_{1}\right)$ and health and usage monitoring systems (HUMS) literature. ${ }^{15-18}$ This is seen, for the purpose of this research article, as a subset of the integrated system health management (ISHM) and integrated vehicle health management (IVHM) approaches ${ }^{19,20}$ which seek a service support and management philosophy employing the use technical data gained by applied sensors in 'real time'. The data, information and knowledge gained can then be used to support 'use or maintain' decisions thus maximising availability.

In parallel with the dynamic gathering of performance knowledge, there is a plethora of performance data, information and knowledge that can be obtained from the maintenance, repair and overhaul (MRO) function within the service delivery system. This offers discrete explicit and tacit knowledge relative to component degradation and offers the potential to re-engineer components so as to improve service life and availability. $^{21,22}$

The use of real-time performance and degradation data supported by data obtained by the maintenance shops can be said to be subsets of through-life engineering services (TES) which seek to offer technical product support for the whole life cycle of the manufactured product. TES uses this greater technical understanding to develop products that maximise their availability for use and offers decision support and costing solutions in support of sustainable solutions. While research in dynamic monitoring, diagnostics and prognostic assessment of products has been growing over the last 20 years, interest in harvesting MRO acquired data and linking it to the IVHM philosophy to develop a TES business paradigm is relatively new. This research seeks to focus on the MRO elements of the TES service delivery system.

In so doing, the research sees the aim of TES as a concept which seeks to improve value, customer satisfaction and retention through the provision of technical services which go beyond the technical capabilities to extend ... quality of service ... [seeking to provide the] ... required and predictable performance of a complex engineering system throughout its operational life with optimum whole life costs. $^{23}$

TES as an emerging product support system serves to increase the availability for use of the manufactured product. The level of data that MRO systems provide offers the ability to 'design out' product/system fault mechanisms through effective feedback of MRO information and knowledge to both product design and manufacturing functions within the organisation.

The distinction between $\mathrm{CBM}_{1}$, condition-based maintenance $\left(\mathrm{CBM}_{2}\right)$ and condition-based management $\left(\mathrm{CBM}_{3}\right)$ as discussed in the literature can be confusing as they all use the same abbreviation, namely, CBM. For clarity, this article identifies the concepts by adding suffixes to the abbreviations, namely, condition-based monitoring $\left(\mathrm{CBM}_{1}\right)$, condition-based maintenance $\left(\mathrm{CBM}_{2}\right)$ and condition-based management $\left(\mathrm{CBM}_{3}\right)$.

Section 'Research methodology' of this article presents the research methodology used in conducting this research. The key findings are presented in section 'Key findings from the survey results' followed by discussion in section 'Discussion of the survey findings'. A summary of the key findings and discussion can be found in section 'Conclusion'. The article will show that while the literature holds 'insights' relative to TES by reference to published articles in the fields of $\mathrm{CBM}_{2}$, IVHM, diagnostic and prognostic technology applications and product life-cycle management (PLM), they are fragmented with no holistic study emerging. The findings of the survey also illustrate this within the practitioner base. The article identifies that that there are many issues to address in both 'hard' and 'soft' technologies relating to whole life product support. The article is a contribution to the understanding of the adoption, application and awareness of TES in support of PSS and servitisation solutions. It reports upon the exploratory stage of research relating to the characterisation of 'in-service' feedback for component design and manufacture (papers forthcoming). Finally, practitionerperceived opportunities and challenges relating to the adoption of TES are reported together with identified inhibitors to success.

\section{Research methodology}

The research methodology chosen is that of the survey. The questionnaire obtains both quantitative and qualitative data from manufacturing organisations identified as offering or intending to supply MRO activities in support of their product. The research methodology consists of four phases and is illustrated in Figure 1. 


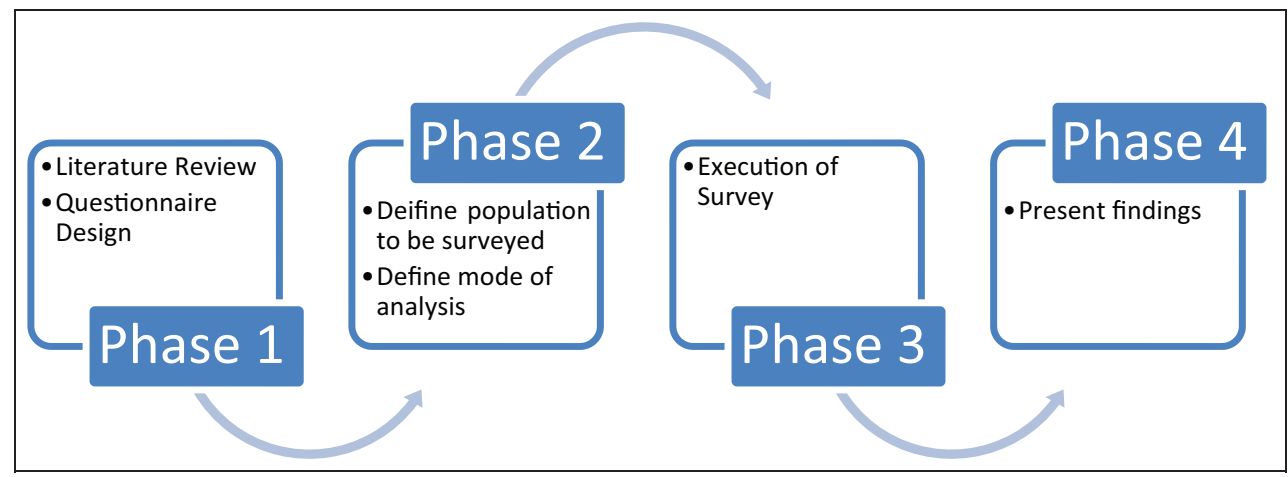

Figure I. Overview of the research methodology.

\section{Phase I: literature review and questionnaire design}

The literature search strategy is formulated by initially identifying the sources from which the data within the literature can be obtained, the time frame for contributions and the keywords/search strings informed by the initial articles selected. In selecting the data sources, standard library e-resources were identified by choosing 'Engineering' and 'Manufacturing and Creative Design' as top-level filters. The second-level filters chosen related to 'Reliability and Maintenance', which lead Scopus, ABI Inform, AIAA, Association of Computing Machining, Business Sources Complete, IEEE Xplore and Web of Knowledge being chosen. The time frame selected included only contributions to the literature that were between 2000 and 2013. In searching the literature, keywords and search strings emerged that had perceived relevance to TES. TES are seen as a broad concept relating to engineering product support offered by increasingly complex service delivery systems. It was therefore necessary to apply a varied number of search strings that would capture the majority of contributions to the literature. Typically, 'total health management', 'condition based maintenance', 'whole life maintenance', 'asset management', 'product life-cycle management', 'autonomous maintenance', 'intelligent maintenance' and 'informed maintenance' were used to identify relevant contributions. In addition, keywords were also applied to the databases which relate to key elements of TES. These included 'Service led design', 'Maintenance, Repair, \& Overhaul', 'Maintenance Systems', 'Self-healing', 'systems integration', 'service led logistics' and 'service standards'.

An overview of the literature relative to TES and related topics forms the grounding for this research. The subsequent survey is informed by a review of the literature relative to $\mathrm{CBM}_{1}, \mathrm{CBM}_{2}, \mathrm{CBM}_{3},{ }^{15,24-26}$ IVHM, ${ }^{27-30}$ prognostic and diagnostic technology application, ${ }^{31-33}$ MRO support and knowledge management systems ${ }^{34}$ and PLM. ${ }^{35,36}$

In seeking to offer a definition of TES, one sees no definitive descriptor emerging. It can be noted, however, that the enabling currency facilitating service support is knowledge. That is knowledge of the mode of use, knowledge of the degradation mechanisms applicable to the product and knowledge of mitigation and repair methods used to reduce degradation rate and finally restore design functionality. Only by acquiring and applying such knowledge can a product's service delivery system be effective. The research first asked the question 'What is knowledge?' and then went further to seek the answer to the question 'What is service knowledge?'.

The literature offers much by way of contribution relative to 'knowledge' and 'knowledge management' which is a major field of investigation, research and application in its own right. The literature defines knowledge as either tacit or explicit. ${ }^{37,38}$ Explicit knowledge can be articulated and codified by way of a formal language which may be textual, numeric or alphanumeric $^{39}$ and is a typical resultant from the collection of service data once a context to its acquisition is applied. Tacit knowledge by contrast is a collection of understanding and experiences which reside in the individual or the collective and has two distinct components. The technical component resides in the practical skills and product/process employed in understanding tasks by is not codified. The second element is cognitive and evolves from the beliefs and viewpoints of the individual and is difficult to disseminate.

It is suggested by this research that the capability of sharing knowledge content, context and meaning with other sources is a key enabler of servitisation, as companies adopt ever more complex service delivery systems. As the organisation moves from providing base service (product supply and spares), through everincreasing levels of service to ultimately availability contracting ${ }^{14}$ supported by monitoring technologies, ${ }^{19}$ the ability to develop, store and recall such knowledge becomes essential to support the product. In engineering services, the use of such knowledge facilitates change. Such change can be either a reactionary (by way of mitigation or repair) or an action resulting from prognosis based on such data, information and therefore knowledge. In consideration of these insights into knowledge, the following definition for service knowledge is offered: 


\begin{abstract}
Service knowledge is the ability to initiate a change of state in a product or asset, facilitated by awareness of the current condition of that product or asset, its historical usage, and means of restoring the 'as designed' functionality supported by explicit (codified) and tacit knowledge of the degradation and failure mechanisms of that component. (Paper forthcoming)
\end{abstract}

The concept of service knowledge is seen as being a facilitator of product support services. The application of the above definition of service knowledge, its content and context is used to offer a definitive descriptor for TES, that being

Through-life Engineering Services are the application of explicit and tacit 'service knowledge' supported by monitoring, diagnostic, prognostic technologies and decision support systems whilst the product is in use, and the application of maintenance, repair and overhaul functions to mitigate degradation, restore 'as designed' functionality, thereby maximising product availability, thus reducing whole life cost. (Paper forthcoming)

In offering this definition, several questions naturally arise when considering MRO activities in support of manufactured complex engineering products throughout their life. Organisations routinely collect vast amounts of performance data while the product is in (or after) use through the application of various monitoring technologies and solutions. ${ }^{15,16,18,25}$ This is supported by both the explicit and tacit maintenance knowledge that is held within the maintenance and repair facility. This research seeks to understand how these knowledge assets are used to inform the design and manufacturing functions with a view to facilitate ever greater levels of servitisation, which in turn delivers greater product availability for use.

In seeking to gain this understanding within the UK manufacturing population identified, several top-level research questions are posed. They are as follows:

1. What are the major challenges and opportunities which relate to MRO activities across core industry sectors?

2. What are the major challenges and opportunities relative to the feedback of service knowledge to the design and manufacturing function across industry sectors?

3. How can case studies be identified and captured illustrating how both design and manufacturing issues impact upon service performance, and as a result whole life cost?

4. Can the identified challenges and opportunities be mapped to identify any future research opportunities?

5. How might the future research field support identified requirements from industry relative to TES?

These questions present the general theme of the study and the basis from which the questionnaire is designed. When reviewing the questionnaire design (see Appendix 1), it is seen that it is divided into five sections that contain a total of 40 questions. The first section seeks to identify the sector in which the respondent organisation operates, its position in the value chain and its organisational structure. In addition, information relative to the type of manufactured products offered and to whom is also sought. The second section seeks information relating to how each organisation delivers service provision to its customers (or product users) and the means by which the requirement for service is triggered. The method of recording data obtained from service activities is also sought together with requests for knowledge of the purpose and use of acquiring such data. The section also identifies the level of feedback of such data to both manufacturing and design functions within those organisations who responded. Section 'Key findings from the survey results' seeks to identify the major challenges to be overcome relative to MRO activities when seeking to inform both the design and manufacturing functions of the organisation. Section 'Discussion of the survey findings' identifies the major opportunities existing from the same perspective. The final section of the questionnaire investigates the future plans relative to the adoption of TES for each organisation and threats to the success of those plans.

\section{Phase 2: define the scope of the survey population and mode of analysis}

This research adopts the survey population defined in previously reported work ${ }^{33}$ and is supplemented by contacts known to the researchers by way of convenience sampling. This is deemed suitable for this study when reviewing how the population was defined (Table 1).

These search parameters were entered into the Forecasting Analysis and Modelling Environment $(\text { FAME })^{\circledR 40,41}$ database which currently contains the details and ownership of approximately 3,500,000 companies within the United Kingdom. The filters within the database were set to those listed in Table 1 and in addition Standard Industrial Classification (SIC) coding was used to further filter out companies who were out of the scope and focus of the study. The database returned a list of 1850 organisations that were adopted as the initial database for the survey. The mode of

Table I. Defining the survey population.

\begin{tabular}{ll}
\hline Definition of & All manufacturers within the United \\
survey population & Kingdom \\
& Manufacturing operations are actually \\
within the United Kingdom & Recorded turnover is over $£ 10$ million \\
& They trade in the B2B sector
\end{tabular}

B2B: business-to-business. 
analysis applied to the returned data is that of descriptive statistics for the encoded quantitative data and verb analysis for the qualitative (text-rich) data. It is important to note that while the data cannot offer any inference against a mean (due to its being categorical in nature), ${ }^{42}$ the methodology does present findings that are both informative and offer direction for future research.

\section{Phase 3: execution of the survey}

In seeking to survey all 1850 organisations returned from the FAME database, a secondary-level filter of reviewing each company website was employed. The rationale for this stage of the survey was the assumption that 'manufacturers who were actively engaged in developing ... [TES] ... capabilities would exhibit evidence of this in publicly available data'. ${ }^{33}$ While Grubic et al. ${ }^{33}$ acknowledge that there are limitations to this approach, the method is still adopted for this study due to resource and timing constraints when conducting this phase of the research. ${ }^{33}$

A review of all 1850 company websites sought to identify which organisations either explicitly stated that they offered 'intermediate' or 'advanced' services (and in particular TES generic services) or made statements that implied that they did, or were in the process of evolving them. Where there was doubt, the organisation was included in the final sample. This resulted in a population of 404 organisations being targeted for receipt of the questionnaire. While the 404 companies identified serve as a defined population of organisations that fit the search and filtering parameters, they are also a stratified sample of the total population of UK-based manufacturing organisations listed within the FAME database.

The questionnaire was sent to all organisations identified within the population during January 2012 and data were collated at the end of February 2012 supported by an 'open' online survey which was launched on 18 January 2012 and closed on 18 April 2012. The questionnaire was sent to managing directors, senior executives and managers within all the manufacturing organisations identified. A team of researchers and support staff conducted follow-up telephone calls to ensure that the survey had been received and to ensure that there were no difficulties that would impact upon intended completion. Upon receipt of the returned questionnaires, they were indexed and encoded to protect the identity of each respondent and facilitate ease of data input for analysis. The online survey was widely published through professional networking sites, trade bodies, government agencies (i.e. Manufacturing Advisory Board) and trade events, and the returned data were again indexed and encoded.

\section{Phase 4: results and analysis}

Resulting from the review of all the 1850 company websites identified within the survey population, 1446
(78.2\%) exhibited no evidence of offering or developing TES solutions in support of their manufactured products. The remaining $404(21.8 \%)$ of the population who do exhibit explicit or implied evidence of such offerings or the development of TES solutions are therefore the focus of analysis.

Despite follow-up telephone calls made by the research team, the return rate for the postal element of the survey proved to be disappointing with a return rate of $\leqslant 0.5 \%$ being achieved. This is in marked contrast to a previous response rate of $17 \%$ obtained in an earlier study investigating the adoption and use of diagnostic and prognostic technology within UK manufacturers conducted by Grubic et al. ${ }^{33}$ Reasons recorded for this are the current national macro-economic decline of the UK economy (2011 media), significant levels of company liquidations and other miscellaneous trading conditions being cited for organisations not wishing to engage in the survey.

The on-line element of the survey, while not having the same level of statistical rigour relating to the identity and categorisation of respondent organisations, achieved a notional return rate of $17 \%$ based on an assumed sample size of 300 . The purpose of the survey is to gain a 'feel' for the cross-sector challenges and opportunities identified from the practitioner perspective relating to TES. The findings will be used to inform and define further cross-sectional and longitudinal case study research initiatives. While the descriptive statistics cited within this article serve as comment relative to the practitioner viewpoint, they cannot make inference towards a mean or make assumptions relative to the total population of those surveyed. This article reports upon the findings of the on-line survey only as there is a risk of double counting should both sample sets be merged.

\section{Key findings from the survey results}

Of the 51 organisations responding to the on-line survey, $86 \%$ stated that they operated in the aerospace sector. Other sectors include defence $(21 \%)$, nuclear $(10 \%)$, automotive, electronics, energy, marine, oil and gas $(3 \%)$ and telecom $(4 \%)$. While it should be noted that several organisations state that they operate in several sectors, the data illustrate that no organisations from health or mineral extraction sectors responded although the literature does contain examples of TES applications from these sectors (quarry trucks, drilling equipment, medical scanners, etc.).

When seeking to understand the respondent organisation's position in the value chain (Question 1.2), it is seen that the majority are found to be original equipment manufacturers (OEMs) (23\%) with Tier 1 suppliers $(18 \%)$ and Tier 2 suppliers $(16 \%)$. All the organisations state that they either manufactured complex electro-mechanical products and/or were involved within MRO activities at varying levels (Question 1.4). 
Table 2. Cross tabulation (Questions I.5 and I.7) - identity and description of customers for organisations responding to the survey.

\begin{tabular}{lllll}
\hline $\begin{array}{l}\text { Q7. How would you describe your } \\
\text { industrial/commercial customers? }\end{array}$ & $\begin{array}{l}\text { Q5. Government agencies? } \\
\text { (transport, defence, etc.) }\end{array}$ & $\begin{array}{l}\text { Q5. Public/private } \\
\text { companies? }\end{array}$ & Q5. Consumers? (B2C) & Other \\
\hline $\begin{array}{l}\text { Q7. Government agencies } \\
\text { (transport, energy, defence, etc.) }\end{array}$ & 10 & 6 & 1 & 2 \\
$\begin{array}{l}\text { Q7. Predominantly large } \\
\text { organisations }\end{array}$ & 16 & 22 & 3 & 4 \\
$\begin{array}{l}\text { Q7. Predominantly SMEs } \\
\begin{array}{l}\text { Q7. No industrial or commercial } \\
\text { customers }\end{array}\end{array}$ & 2 & 7 & 2 & 2 \\
\hline
\end{tabular}

B2C: business-to-consumer; SMEs: small to medium enterprises.

In seeking to identify the customer base for the respondent organisations (Question 1.5), choices of government agencies, public/private companies or business-to-consumer (B2C) transactions were offered while leaving the option to state other relationships. The data when cross tabulated with the data obtained from Question 1.7 (a description of their industrial/commercial customers) present the following observations (Table 2).

It is seen that of those organisations responding, their customers are predominantly large public or private companies or government agencies with relatively few being small to medium enterprises (SMEs). The findings also show that $64.3 \%$ of respondent organisations offer in-house service operations in support of their manufactured products (Question 2.1). When wishing to know how these services are triggered (Question 2.2), 32.1\% state that these are triggered by a customer request with only $7.1 \%$ stating that the manufacturing organisation initiated MRO activities themselves. The majority $(60.7 \%)$ of respondents stated that they used a combination of both 'customer/user initiated' (reactive) and manufacturer (proactive) triggers to initiate maintenance and service activities. The means by which manufacturers triggered MRO activities (Question 2.3) are shown in Figure 2.

Questions 2.4-2.7 sought to identify how each of the differing maintenance systems was delivered. The analysis of the responses applied to the qualitative 'text' data offered no clear consensus or direction. However, for 'condition monitoring systems', the keywords identified in the responses related to 'data', 'engine', 'systems' and 'information sharing'. As expected, the majority $(96.4 \%)$ of all respondents stated that they did record $\mathrm{MRO}$, findings and observations resulting from MRO activities (Question 2.8).

The recording of data is found to be undertaken using a variety of methods ranging from traditional paper documentation, through electronic data capture and radio-frequency identification (RFID)-related technology, to state-of-the-art remote data acquisition and recording using condition monitoring supported by telecommunication and/or satellite enabled systems (Question 2.9) (Figure 3).

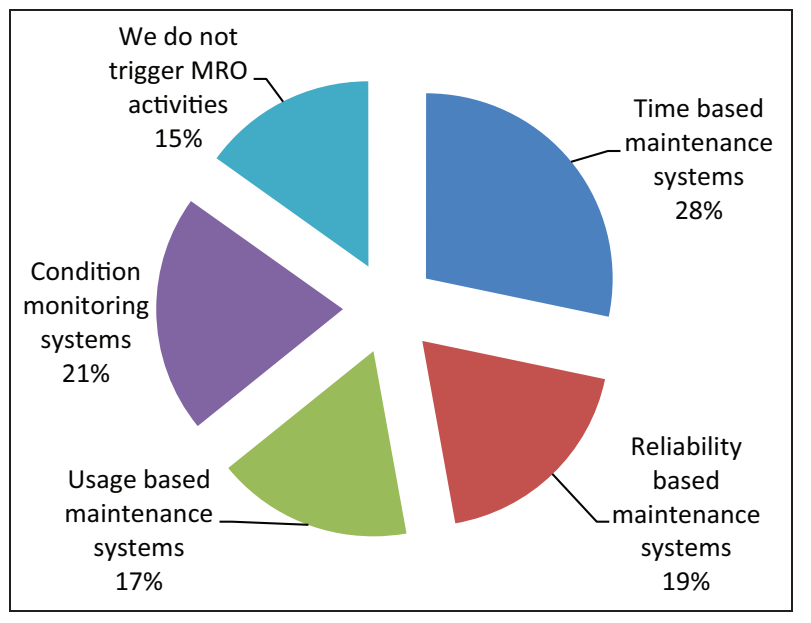

Figure 2. Method by which MRO activities are triggered within respondent organisations.

MRO: maintenance, repair and overhaul.

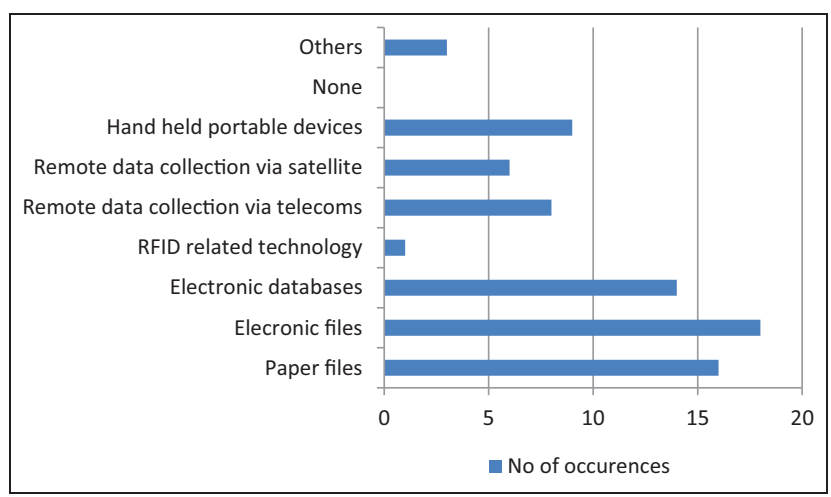

Figure 3. Method of recording MRO data within respondent organisations.

RFID: radio-frequency identification.

In more advanced $\mathrm{CBM}_{1}$ systems, the qualitative data suggest that once data have been imported into organisational design databases some businesses have the ability to immediately take advantage of the data by propagating and including it throughout the entire diagnostic (including product health management 
systems) design (Question 2.10). One respondent organisation states that

... once integrated, which is nearly instantaneous, it (the entire diagnostic/PHM system design) is able to be simulated, enriched, shared over the web, integrated with publications, determine impact of systems level ... [via simulation] ... WHILE taking maintenance into consideration .... (Ref: data)

Finding 1. Although there is continuing growth cited within the literature relating to proactive MRO initiatives, the data suggest that such activities for the majority of manufacturing organisations responding to the survey appear to remain reactionary only being triggered by customer request.

Finding 2: The data suggest that there is no clearly defined universal method adopted by MRO activities for the collection of data with such functions using a variety of data collection protocols and methods.

The question that naturally arises at this point is to what use are the data applied once obtained? (Question 2.10). Of the options presented in the questionnaire, 'billing' and 'spares and inventory acquisition' are found to be the most common use (29\%), while $23 \%$ stated that it was used for 'usage monitoring', and 20\% state that they used the data for 'assisted time based MRO systems'. Significantly no responding organisations stated that they used such data for cost modelling. This partly supports recent findings within the literature which state that 'there is presently no study on cost estimation of availability type contracts in the literature'. ${ }^{43}$ It is suggested that subjective expert opinions are used to assess MRO life-cycle costs that are limited due to reliability of the data, and assumptions made relative to failure modes. ${ }^{43}$

Further analysis relating to use of the data revealed that it was used for 'training purposes', 'diagnostics', 'prognostics', 'life-cycle predictions' and 'reliability analysis'. It is also significant to observe that the MRO and condition data obtained within the respondent's organisation do get fed back to both the design and manufacturing functions within the supply chain (Questions 2.10 and 2.11) ( $25 \%$ of organisations responding to the survey feed data back to either design or manufacturing functions).

Finding 3. Within the organisations surveyed, the majority of organisations state that they DO feed back MRO data to their design and manufacturing functions (either in house or external). This implies that such data are technology/usage based rather than being purely commercial or administrative.

When seeking to understand the content of data fed back to the design and manufacturing functions (Question 2.14), an analysis of the textual responses illustrates that 'failure modes/categorisation' and 'performance' data were the main items fed back. It is also noted that organisations state that it helps them formulate costs. One particular response is quoted as it serves to summarise the response to this question (2.14):

... [this] ... is yet to be investigated, but in short the information would ... [typically] ... include symptom data (where applicable), life cycle data with respect to the end user, modification state (software \& hardware) etc .... (Ref: anonymous: survey data response)

Section 'Key findings from the survey results' of the questionnaire seeks to identify the challenges as perceived by practitioners relating to the capture, structure, storage and retrieval of MRO data. The section also identifies the systems in use within the respondent organisations for data analysis, technologies employed in conducting MRO activities and the perception of practitioners as to future technological innovations which are required within the $\mathrm{MRO}$ arena in the next 5 years. A review of the written responses to the question '... what are the challenges relating to the capture of MRO data?' (Question 3.1) shows the following (Figure 4).

The figure records the keywords identified from the analysis of the responses and the magnitude of each word gives an indication of the frequency of occurrence with reference to the others identified. The responses suggests that there are issues with the quantity, quality and completeness of the data which require resolution while indicating that there are problems with the effectiveness of the feedback system mechanisms. One respondent states that issues arise '... from end user (symptom/usage profiles and problems) to maintenance to design/R\&D' (ref: anonymised respondent). In addition, the structure and consistency of the data are seen to be a problem and there appears to be a misalignment in the requirements for $\mathrm{MRO}$ data and the system specifications that seek to capture the data. These issues point to a requirement for standards (and procedures) as the data state that there is need for further work relating to definitions, taxonomy and ontology to promote a common understanding. This is due to the complexity of the service (MRO) offerings and is confirmed when reviewing the responses to Question 3.2 relating to the structure of the data. The majority of comments point to a need for standards in this area and in some

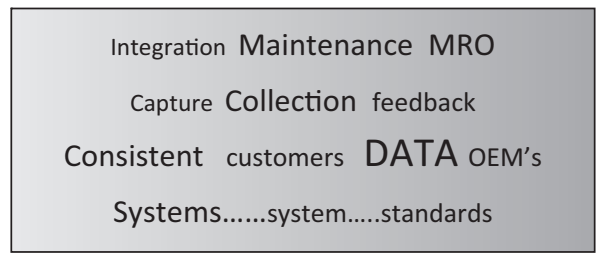

Figure 4. Analysis of data returned when seeking the challenges relating to the capture of MRO data.

MRO: maintenance, repair and overhaul. 
cases practitioners state that industry standards (where they exist) are not adhered to within MRO functions.

The data also suggest that OEMs have advanced to a level that far surpasses other organisations within their supply chains. Typically, non-OEMs lack the capital and infrastructure to pursue advanced MRO initiatives within the TES field which impedes their attempts to formulate effective feedback systems, the data content being too difficult and fragmented to bring together to enable any database to effectively drive the MRO activity. This is reflected in the literature. Such companies documented tend to the market leaders (Rolls Royce, GE, Caterpillar, Siemens, Xerox, MAN Trucks, Bombardier Trains, etc.).

Finding 4. There appears to be a misalignment relating to the needs of the end user of MRO data (manufacturing and design functions), and the system's abilities to provide accurate and timely responses (technical and usage data) and related information.

Finding 5. Challenges exist relating to the quantity, quality and completeness of data. Respondents to the survey suggest that there are too much data, it is fragmented and of poor quality in many cases and not complete.

Finding 6. Within the MRO field relating to TES, there are no clear definitions, ontology or taxonomy which can assist in the categorisation of data, information and ultimately knowledge.

The issue of 'No Fault Found' (NNF) is also raised when enquiring about the structure of the data (Question 3.2). The responses suggest that there could be too much of a focus on corrective maintenance diagnosis and rectification which is predicated on hard faults which '... fail[s] to consider the very different implications of intermittent faults ... [or errors and faults which are subsequently not found] ...' (ref: anonymised respondent). This inferior relationship between symptoms, fault identification and repair skews the MRO data and analysis which in turn could affect maintenance and supply chain decisions.

Finding 7. There are issues relating to incomplete understanding of product and component performance due to intermittent failures and error signals in MRO systems. This skews the data and can affect decisions relating to $\mathrm{MRO}$ strategies.

The retrieval of MRO data (Question 3.4) also presents some major challenges. Overwhelmingly, practitioners cite 'accessibility' as an issue that needs to be addressed. The data tend to be manipulated to suit individual organisation's needs with classification being unfriendly and with the data being difficult to 'drill down' and interrogate. In addition, the amount of data that can be obtained cause problems with it being held in too many locations and in too many propriety formats. Organisational system silos exist with many data still held in $30+$ year systems (typically, Fortran 77, TPF, Cobol and Adabas) being common. This results in data being extremely difficult to collate and assemble into a common database from which MRO operational decisions can be made.

Finally, section 'Key findings from the survey results' of the questionnaire enquires about issues relating to data analysis. Although the majority of organisations responding $(70 \%)$ stated that they possessed systems that were capable of analysing MRO data (Question 3.5), the qualitative responses to this question suggest that many organisations do not conduct any analysis of MRO data. This does not imply that respondent organisations do not feed data back to the design and manufacturing functions. Of those that did state that they analysed the data, physics-based models and finite element analysis appear to be used.

Finding 8. Although organisations stated that they collected MRO data, its content, structure, storage and retrieval appear to be ad hoc in all but a few leading world-class OEMs. The data are unduly skewed by the existence of NNF recording within the data, the effect of which is not clear or widely known.

It is seen from the results presented that there is room for innovation within this arena. Practitioner's opinion was sought (Questions 3.6-3.8), and the returned responses were analysed. The findings of this analysis are presented in Figure 5.

In reviewing Figure 5, one sees an improved ability to accurately diagnose and report faults to MRO departments required which will align such data and MRO initiatives providing an augmented reality to the whole process. This is supported by standardisation within the fields of data collection and reporting. Practitioners also point to the use of RFID applications as an innovative means of data capture and reporting. Consistently, it is seen throughout the responses that the importance of $\mathrm{CBM}_{1}$ (and management) is growing as organisations see and understand the potential advantages of this technology application. $\mathrm{CBM}_{3}$ 's ability to rapidly detect, locate, isolate and in certain cases mitigate error signals from degrading components and systems is also important to reduce NNF problems that attribute to $30 \%-50 \%$ of one respondent's MRO

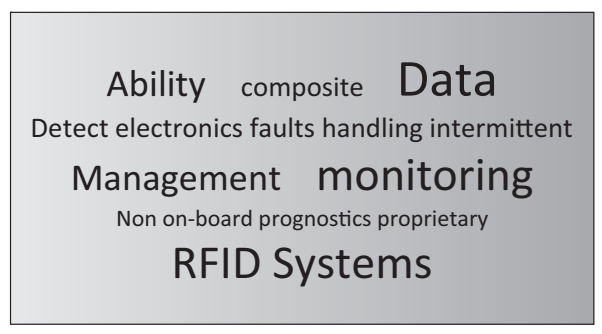

Figure 5. Future initiatives defined by practitioners identified by data cloud analysis. 


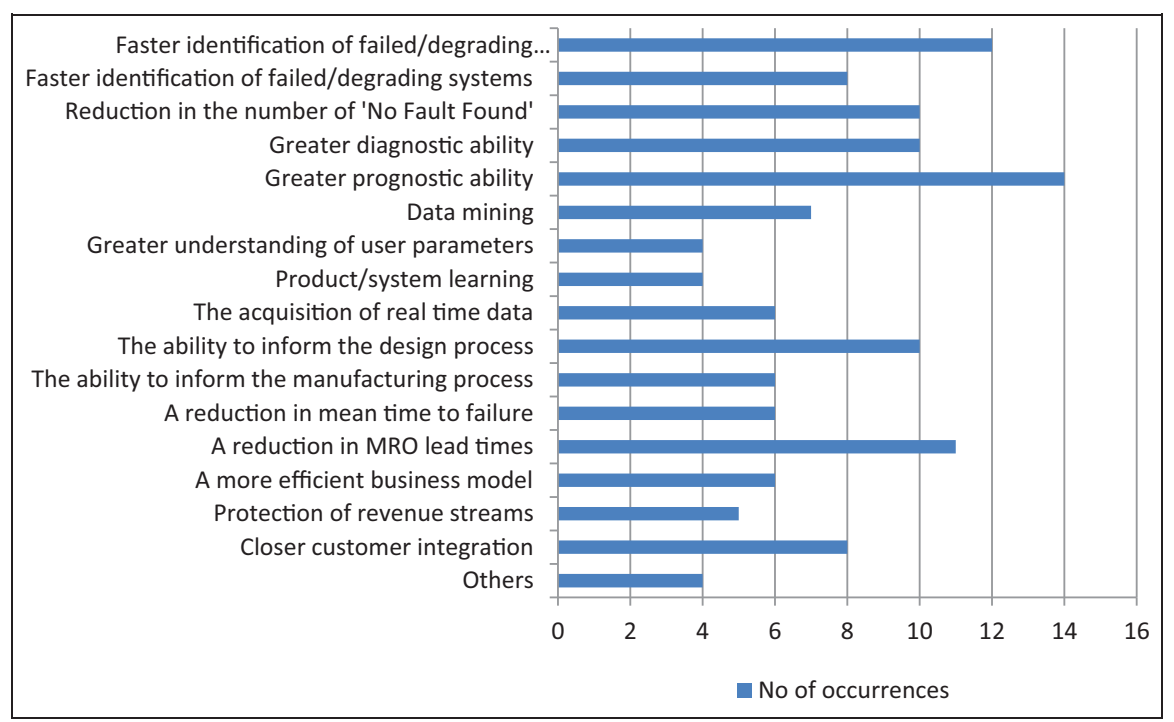

Figure 6. Opportunities perceived as being of greatest importance by practitioners.

MRO: maintenance, repair and overhaul.

issues (source: survey respondent). The survey also identifies from a set of opportunities documented within the MRO literature practitioners' perception of which are the most important (Figure 6).

Figure 6 illustrates that prognostic and diagnostic capabilities are important opportunities to be addressed accompanied by the resolution to the NNF problem. The need for faster identification and response to failing/degrading products and systems is also a priority supported by $\mathrm{CBM}_{3}$ solutions. These findings imply that the ability to reduce the MRO costs and increase mean time before failure (MTBF) through the application of efficient diagnostics and prognostics supported by the ability to inform the design process is enabler to a more efficient business model and reduced risk to revenue streams. However, given that these opportunities for the business are identified in both the literature and the practitioner base, it is interesting to note that when asked if each organisation had a formal corporate strategy to develop these areas, $47 \%$ said yes and $34 \%$ no with $18 \%$ stating that they did no know. There is no definitive response when the organisations were asked if they had a formal strategy to develop the feedback from the MRO function to either design or the manufacturing functions ( $\sim 39 \%$ yes, 30\% no, 30\% did not know).

Finding 9. $\mathrm{CBM}_{1} /$ management and RFID technology are identified as being the key opportunities within the field of TES.

The final section of this survey seeks to identify each organisations' future plan within the field of TES. Of those organisations that did respond, the majority $(67 \%)$ expressed plans to adopt these services while $71 \%$ stated that they did have plans to use the data obtained through the MRO function to feed back into both their design and manufacturing functions. The reasons cited for pursuing these opportunities vary from being driven by external forces (Strategic Defence Review - organisations producing military equipment), to commercial interests (asset residual value, asset availability, protection of revenue streams, sharing of risk). When asked of the perceived threats to the successful achievement of these opportunities, a lack of standards, non-standard processes, consistency of purpose, aligned operational structure, culture, haphazard prognostics and short termism of investors all emerged as potential inhibitors.

Finding 10. Interest in TES continues to grow. The majority of organisations responding to the survey state that they have plans to move into TES with a greater majority stating that they have plans to extend the use of acquired MRO data and use this to inform the manufacturing and design functions within their organisation.

Finding 11. While there are undoubtedly significant challenges and opportunities relating to the successful adoption of TES, the perceived threats to this successful adoption within the practitioner base responding to the survey relate to data management issues arising from lack of standards, procedures and supporting structures.

\section{Discussion of the survey findings}

The research posed several top-level questions that serve as waymarks for the ongoing study.

\section{The major challenges and opportunities relative to $M R O$ activities}

The findings illustrate that there are many challenges to be overcome and opportunities to realise within the TES arena. The adoption of TES is driven by organisations that manufacture high-value complex products and hold a position at high end of the value chain (Findings 1 and 2). This concurs with the literature. ${ }^{44} 46$ When looking at the cited contributions relative to CBM, IVHM, HUMS and PLM, one sees that all the products can be seen to be complex mechanical, electro- 
Table 3. Summary of survey findings.

\section{Findings}

I. Although there is continuing growth cited within the literature relating to proactive MRO initiatives, the data suggest that such activities for the majority of manufacturing organisations responding to the survey appear to be mainly reactionary, only being triggered by customer request.

2. The data suggest that there is no clearly defined universal method adopted by MRO activities for the collection of data with such functions using a variety of data collection protocols and methods.

3. Within the organisations responding to the survey, the majority of organisations state that they do feed back data to their design and manufacturing functions (either 'in house' or external). This implies that such data are technology/usage based rather than being purely commercial or administrative.

4.

There appears to be a misalignment relating to the needs of the end user of MRO data (manufacturing and design functions) and the system abilities to provide accurate and timely responses (technical and usage data) and related information.

5. Challenges exist relating to the quality, quantity and completeness of data. Respondents to the survey suggest that there are too much data, they are fragmented and of poor quality in many cases and seldom complete.

6.

Within the MRO field relating to TES, there are no clear definitions, ontology or taxonomy which can assist in the categorisation of data, information and ultimately knowledge.

7. There are issues relating to incomplete understanding of product and component performance due to intermittent failures and NNF error signals in MRO systems. This skews the data and can affect decisions relating to $M R O$ strategies.

8

Although organisations stated that they collected MRO data, its content, structure, storage and retrieval appear to be ad hoc in all but a few leading world-class OEMs. The data are unduly skewed by the existence of NNF recording within the data, the effect of which is not clear or widely known.

9. Condition-based monitoring/management and RFID technology are identified as being key opportunities within the field of TES.

10 Interest in TES continues to grow. The majority of organisations responding to the survey state that they have plans to move into TES with a greater majority stating that they have plans to extend the use of acquired MRO data and use this to inform the manufacturing and design functions within their organisation.

II. While there are undoubtedly significant challenges and opportunities relating to the successful adoption of TES, the perceived threats to successful adoption within the practitioner base responding to the survey relate to data management issues arising from the lack of standards and supporting procedures.

MRO: maintenance, repair and overhaul; TES: through-life engineering services; NNF: No Fault Found; OEM: original equipment manufacturer; RFID: radio-frequency identification.

mechanical high-value offerings. ${ }^{47,48}$ Although the majority of organisations responding to this survey state that they have an interest in TES, their actions, with a few exceptions, appear to still be reactionary (Finding 3). This is in contrast to the literature that presents a proactive approach. ${ }^{12,13,49,50}$ Lee et al. recognises this issue when stating that organisations '... still employ traditional maintenance strategies that do not consider the true condition of the equipment ${ }^{51}$

The nature, structure, content and context of the MRO data collected are also worthy for further investigation. Data storage and management systems through effective portals and platforms are also revealed as a problem within those organisations taking part in this research. Some databases are not integrated and have evolved in a fragmented way resulting in silos of data existing in differing formats causing major issues when seeking to merge data to obtain knowledge of performance from which MRO decisions can be made based on prognostic techniques. This is an issue with MRO operations dealing with legacy systems. By contrast, however, in some of the major OEMs, it is seen that technology applications such as telecommunications, sensors, decision support and RFID are enabling state-of-the-art condition management solutions to develop. ${ }^{52-56}$

\section{The major challenges and opportunities relative to in-service feedback to design and manufacturing functions}

The majority of organisations answering the questionnaire state that they do feed back MRO data to their design and manufacturing functions (Finding 4) and service supply chain. The findings suggest, however, that the majority of the data are used for administration, commercial, financial and or statutory use (statutory Health and Safety Executive and insurance inspections, etc.). This implies there is little product/ process re-engineering taking place employing the MRO data in a significant proportion of organisations responding to the survey. This observation is surprising. The literature is full of examples that cite the benefits of CBM, HUMS and IVHM data use and how it may be used to mitigate risk to revenue streams for companies competing by offering advanced services. One only has to watch $\mathrm{F} 1$ racing to see how condition monitoring can and does affect product design and manufacturing processes. Interestingly, while F1 teams were identified within the population, none responded to the survey. However, the literature is not so forthcoming with examples of how MRO acquired data, 
information and knowledge may be used to inform design.

The research identifies that although there are silos containing examples of the use of MRO data feedback, the systems and data that are used are misaligned to the needs of the user (Finding 5). The data are said to be too rich, there are too much of it, and they are fragmented and not specific to the needs of the manufacturing and design functions. In addition, the systems used to acquire and categorise the data are not of bespoke design for the purpose required (Finding 6). This is propagated by the lack of a clear set of standards, definitions, ontology and taxonomies relating to TES which can assist in the categorisation of data, information and eventually knowledge (Finding 7).

The existence of intermittent faults and signal errors is also said to cause both confusion and this skews the data preventing accurate analysis of frequency and occurrence. This has a direct impact on the formulation of effective MRO strategies (Findings 8 and 9).

\section{The use of case studies to inform design and manufacturing impact upon service performance and how future research in the field may identify requirements from industry relative to TES}

The survey findings lead to the identification of several future opportunities for future research within the field of TES. When practitioners were asked to indicate their perception of which opportunities as identified from the literature were of the greatest importance (Question 34 ), the data returned are presented as a cross-sector analysis (Figure 7). In looking at the trends, it is immediately observed that the greatest number of responses originate from the aerospace sector. Although the profiles vary in magnitude across sectors, it is seen that they, while exhibiting variance, follow a similar trend. Of those sectors reported, it is seen that in the aerospace sector prognostics is seen as the greatest opportunity followed by a reduction in MRO lead times, the ability to inform design and closer customer integration. This, however, is hardly surprising as such integration would be required if access to both condition and usage data is to be obtained through which meaningful product performance and MRO knowledge can be developed. The defence and electronics sectors exhibit similar trends with NFF issues being identified as being of increased interest within the electronics, defence and aerospace sectors.

In reviewing the findings, there are several opportunities to develop case studies based on organisations that are at the forefront of TES adoption and also those who are just moving into the servitisation route by adoption of such technical solutions. It is seen from both the literature and the survey that for all but a few leading organisations, TES is a reactionary response to market pressure and not a proactive initiative although this is changing (Finding 1). Further work can be undertaken in this area to understand the drivers and inhibitors to the adoption of TES from a point of the service delivery system and aligned operations strategy formulation. This article focuses on the MRO activities that can support and facilitate an effective through-life service delivery system while acknowledging that there are many other dimensions to product support, both technical and structural. Typically, case studies could be

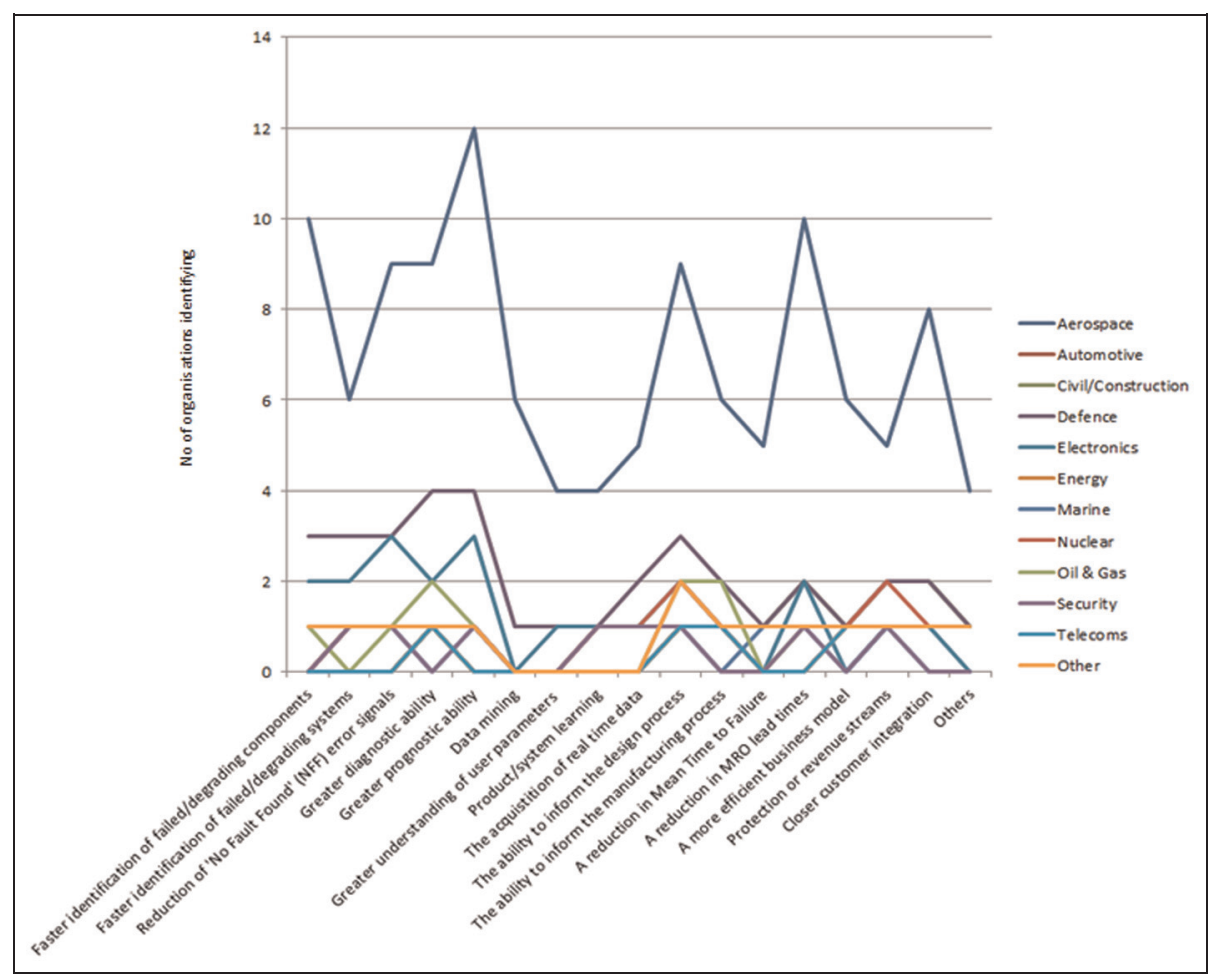

Figure 7. Identified cross-sector opportunities as perceived by practitioners. MRO: maintenance, repair and overhaul. 
undertaken within the field of MRO data harvesting, sorting and trending (Finding 2). Organisations responding to the survey state that the issue is that there are too much data and that most of them can be described as 'noise' (Finding 5). This is seen when reading research initiatives relating to 'Big Data' and the need for systems that can handle, sort and trend such data. Data are of itself inert and a pure record of an event. It needs a context before it can become useful information, and further development before it can be classed as knowledge. There are many opportunities that exist in order to address this which include the development of efficient algorithms that can collect, sort and present the right data while rejecting noise. Furthermore, within the MRO world, a significant source of data comes from text-rich qualitative sources that are not codified. The codification of data limits reporting of maintenance activities at the point of collection by offering preselected classifications. Upon review of such records, it is seen that there is clearly a need to develop software tools that have the ability to capture such data, trend and self-learn the ontology of failure.

Supporting such initiatives is a need to develop a standard ontology and taxonomy of MRO activities and degradation mechanisms to avoid developing systems in silos (Findings 6 and 11). Such solutions should also be able to interface with existing commercially available systems for trending (i.e. failure reporting, analysis and corrective action system (FRACAS)) and business systems (SAP and PLM platforms). This illustrates the needs for standards within this arena which cover the data content, structure and context for given sectors, applications, reporting and degradation classifications (Finding 11). Such standards should also cover the system architecture that is to be developed.

\section{Conclusion}

This research seeks to gain understanding of the level of adoption and use of TES within UK manufacturing organisations. While the literature holds insights into the content, issues and challenges surrounding TES $\left(C B M_{1}, C B M_{2}, C B M_{3}, I V H M, I S H M, P L M, M R O\right.$ and asset management literature), such contributions are fragmented and discursive with no holistic study emerging. This was identified by Grubic et al. ${ }^{33}$ TES is an evolution of service support which seeks to address this issue. The literature relative to the service support of high-value complex manufactured products appears to have two dimensions. First, there is the 'in use' or 'as operated' dimension. This focuses on $\mathrm{CBM}_{1-3}$, IVHM and ISHM technology applications which seek to monitor product condition in real time (or close to real time) and make diagnostic and prognostic decisions relative to operating condition and the remaining operating life prior to the need for service intervention due to the degradation of operating parameters. The literature holds a plethora of contributions relative to these initiatives which discuss engineering, technical, business applications, challenges and opportunities. The second dimension is that of the MRO function. Here, the product has arrived at the MRO facility, is stripped down, fault diagnosis and repair sentencing are conducted, activities to restore the 'as designed' operating condition are undertaken and the return to service is achieved. The activities in both these dimensions are conducted throughout the operating life of the product, but the literature makes little attempt to address this total service support as a single entity. The findings of this survey suggest that this is true within the practitioner population questioned when one reviews the findings reported.

TES is offered as a concept that is the sum of these two dimensions, the aim of which is presented in section 'Introduction' of this article with a definition presented in 'Phase 1: literature review and questionnaire design' which is grounded in the literature (see section 'Acknowledgements').

This exploratory research identifies that there are many issues to address in both the hard and soft technologies relating to this whole life product support. The data suggest there to be little in the way of standardisation within the field of TES with no universally accepted definitions, ontology or taxonomy. Research seeking to address these issues is only just emerging. Furthermore, it would appear that an improved understanding of how data obtained from MRO activities and condition monitoring can be used to design out product degradation is required. There is a clear need to close the 'product life-cycle information loop' and develop service experience led design. This is also true of product faults induced by the manufacturing process. The effect and presence of NFF error signals are also of concern as it is stated that such events skew the data when analysing levels of occurrence. Such events prove costly due to the MRO resources that they consume and also investigation initiatives that they instigate. The findings of this research give insight into the current position relative to TES and the opportunities that should be pursued. It also illustrates the challenges that are to be overcome when seeking to adopt TES enabled by MRO data capture and feedback in order to facilitate an IPS ${ }^{2}$.

Ongoing and future research opportunities relate to developing an in-depth understanding of the issues identified within this exploratory research. The survey data have identified organisations that are well advanced in the application of TES, both as a means of mitigation for component degradation and failure, and that of a facilitator for product service solutions by way of availability contracting. Typically, it is suggested that such future work could include the following:

1. The development of standards and procedures specifically within the field of TES which relate to other existing and emerging service standards.

2. The development of a clearly defined universal method and system architecture for the harvesting and analysis of MRO data should be developed.

3. There is a requirement for clear ontologies, taxonomies and definitions which are component, feature and failure mode generic and can be applied across sectors. 
4. The development of standard system architectures to capture data, information and knowledge, which could effectively interface with existing software portals. In particular, systems such as FRACAS for trending data and the interface of such system architectures with SAPP generic business systems should be investigated.

5. Several respondents to the survey stated that the trending of data was often skewed by the occurrence of NFF error signals within the data. Research should be continued in this area to increase understanding of these issues and their causes. All these opportunities for further research involve both applied science to develop innovative solutions, and both longitudinal and lateral case studies by way of verification and validation.

\section{Acknowledgements}

The authors would like to thank the staff of the EPSRC Centre for Innovative Manufacturing in Through-life Engineering Services for their help and support in conducting follow-up telephone calls to all organisations surveyed. This article presents the findings of an exploratory survey only. Further publications grounding TES in the literature relative to its motivation, theory and practice are in draft and due for publication 2014/2015: Journal Paper (2014) State-ofthe-art in through-life engineering services. Proc IMechE, Part B: J Engineering Manufacture (in draft); Conference Paper (2014) The role of maintenance, repair, and overhaul (MRO) knowledge in facilitating service led design: a nozzle guide vane case study. In: World asset management conference, Petoria, South Africa (paper submitted) and Edited Book (2015) Through-life engineering services: motivation, theory \& practice. UK: Springer (in draft, Publication date January 2015).

\section{Declaration of Conflicting Interests}

The author(s) declared no potential conflicts of interest with respect to the research, authorship, and/or publication of this article.

\section{Funding}

The author(s) disclosed receipt of the following financial support for the research, authorship, and/or publication of this article: This work was funded by the UK Engineering and Physical Sciences Research Council (EPSRC) through the EPSRC Centre for Innovative Manufacturing in Through-life Engineering Services (grant No. EP/I033246/1).

\section{References}

1. Hill T. Manufacturing strategy: text and cases. 3rd ed. Boston, MA: Irwin/McGraw-Hill, 2000.
2. Treacy M and Wiersema F. The discipline of market leaders: choose your customers, narrow your focus, dominate your market (Expanded edition). New York: Perseus Book Group, 1997.

3. Mont O. Product service systems. Final report for IIIEE, Lund University, Lund, 2000.

4. Mont $\mathrm{O}$ and Lindhqvist $\mathrm{T}$. The role of public policy in advancement of product service systems. J Clean Prod 2003; 11: 905-914.

5. Tukker A and Tischner U. Product-services as a research field: past, present and future. Reflections from a decade of research. J Clean Prod 2006; 14(17): 1552-1556.

6. Baines TS, Lightfoot HW, Evans S, et al. State-of-the-art in product-service systems. Proc IMechE, Part B: J Engineering Manufacture 2007; 221: 1543-1552.

7. Sundin E, Lindahl M and Ijomah W. Product design for product/service systems: design experiences from Swedish industry. J Manuf Tech Manag 2009; 20(5): 723-753.

8. Vandermerwe $\mathrm{S}$ and Rada J. Servitization of business: adding value by adding services. Eur Manag $J$ 1988; 6(4): 314-324.

9. Neely A. Exploring the financial consequences of the servitization of manufacturing. Oper Manag Res 2008; 1: 103-118.

10. Baines TS, Lightfoot HW, Benedettini O, et al. The servitization of manufacturing: a review of literature and reflection on future challenges. J Manuf Tech Manag 2009; 20: 547-567.

11. Baines T, Lightfoot H and Smart P. Servitization within manufacturing: exploring the provision of advanced services and their impact on vertical integration. J Manuf Tech Manag 2011; 22(7): 947-954.

12. Meier H, Roy $\mathrm{R}$ and Seliger $\mathrm{G}$. Industrial product service systems - IPS ${ }^{2}$. CIRP Ann: Manuf Techn 2010; 59: 607-627.

13. Meier H and Kortmann D. Automated processes of industrial product-service-systems: fields of operation and solution approaches. ZWF Z Wirtsch Fabr 2006; 101(10).

14. Cohen MA. Power by the hour: can paying only for performance redefine how products are sold and serviced? 2007, http://knowledge.wharton.upenn.edu/article.cfm? articleid $=1665$ (accessed November 2007).

15. Kurfess TR. Detecting trouble early with CBM. Control Eng 2007; 54(7): 36.

16. Land JE. HUMS - the benefits - past, present and future. Aerosp Conf Proc 2001; 1-7: 3083-3094.

17. He D and Bechhoefer E. Development and validation of bearing diagnostic and prognostic tools using HUMS condition indicators. Aerosp Conf Proc 2008; 1-9: 3622-3629.

18. Parker S. IHUMS and real results: a case study from the UK. In: Jennions IK (ed.) Integrated vehicle health management: perspectives on an emerging field. Warrendale, PA: SAE International, 2011, pp.125-140.

19. General Electric Inc. IVHM technology for Business Aviation, http://foofind.com/en/search/GE's_IVHM technology_for_Business\#!/download/DwXXQ5CN5gash X7h/ge's\%20ivhm\%20technology\%20for\%20business \%20 aviation (accessed 06 January 2012).

20. Baroth EC and Pallix J. Integrated Vehicle Health Management (IVHM) for aerospace systems. In: STARR, Jet Propulsion Lab, California Institute of Technology, Pasadena, CA, 5 July 2006, vol. 44, issue 13.

21. Ross TD. Architects manual, ICAM definition method IDEF0 (DR-80-ATPC-01), April 1980.

22. Mountney S. Acquisition and shaping of innovative manufacturing knowledge for preliminary design. $\mathrm{PhD}$ Thesis, Cranfield University, Bedfordshire, 2009. 
23. Shaw A, Pliska A, Pandy A, et al. Through-life engineering services standards development. In: Proceedings of the 1st international conference on through-life engineering services - enduring and cost-effective engineering support solutions Wiltshire, UK: Cranfield University, 5-6 November 2012, pp.166-173.

24. Gulledge T, Hiroshige $\mathrm{S}$ and Iyer R. Condition-based maintenance and the product improvement process. Comput Ind 2010; 61(9): 813-832.

25. Holguin L. Conditioned based maintenance (CBM). IEEE Autotestcon 2005; 2005: 188-193.

26. Dussault PL. Creating a closed loop environment for condition based maintenance plus $(\mathrm{CBM}+)$ and prognostics health management. IEEE Autotestcon 2007; 1-2: 327-331.

27. Williams ZC. Benefits of IVHM: an analytical approach. Aerosp Conf Proc 2006; 1-9: 3602-3610.

28. Sudolsky MD. IVHM solutions using commerciallyavailable aircraft condition monitoring systems. Aerosp Conf Proc 2007; 1-9: 4169-4176.

29. Redding LE. A strategy formulation methodology for companies seeking to compete through IVHM enabled service delivery systems. PhD Thesis, Cranfield University, Bedfordshire, 2012.

30. Benedettini O, Baines TS, Lightfoot HW, et al. State-of-theart in integrated vehicle health management. Proc IMechE, Part G: J Aerospace Engineering 2009; 223(2): 157-170.

31. Rouet V, Moreau K and Foucher B. Embedded prognostics and health monitoring systems. In: Estc 2008: 2nd electronics system-integration technology conference, Greenwich, 1-4 September 2008, vols 1 and 2, pp.79-83. New York: IEEE.

32. Bonissone PP and Iyer N. Soft computing applications to prognostics and health management (PHM): leveraging field data and domain knowledge. In: Sandoval F, Prieto A, Cabestany J, et al. (eds) Computational and ambient intelligence (proceedings 9th international work-conference on artificial neural networks, IWANN 2007). Berlin, Heidelberg: Springer-Verlag, 2007, pp.928-939.

33. Grubic T, Redding L, Baines T, et al. The adoption and use of diagnostics and prognostics capabilities within UK based manufacturers. Proc IMechE, Part B: J Engineering Manufacture 2011; 225: 1457-1470.

34. Greenough RM and Grubic T. Modelling conditionbased maintenance to deliver a service to machine tool users. Int J Adv Manuf Tech 2011; 52(9-12): 1117-1132.

35. Teresko J. Building PLM's potential (product lifecycle management). Industry Week, August 2005, vol. 254, issue $8, \mathrm{http}: / / w w w . i n d u s t r y w e e k . c o m / p l a n n i n g-a m p-$ forecasting/building-plms-potential

36. Catic A and Andersson P. Manufacturing experience in a design context enabled by a service oriented PLM architecture. In: ASME 2008 international design engineering technical conferences and computers and information in engineering conference, Brooklyn, NY, 3-6 August 2009. New York: ASME

37. Young B, Cutting-Decelle AF, Guerra D, Gunendran G, Das B and Cochrane S. Sharing manufacturing information and knowledge in design decision support. In: Bramley A, Brissaud D, Coutellier D, et al. (eds.), Advances in Integrated Design and Manufacturing in Mechanical Engineering, 2005, Netherlands: Springer, pp.173-185

38. Polanyi M. The tacit dimension. New York: Doubleday, 1966.

39. Easterby-Smith M and Lyles MA (eds). Handbook or organizational learning and knowledge management. 2nd ed. Chichester: Wiley, 2011.
40. Forecasting Analysis \& Modelling Environment (FAME) Database, https://fame.bvdinfo.com/version-2012113/Search. QuickSearch.serv?_CID = 1\&context $=1$ Z897E9MKKPOF8R \&parentcontext $=$ ipaddress (accessed January 2009).

41. FAME, https://fame.bvdep.com/version-20091130/cgi/template.d11?product $=1 \&$ user $=$ ipaddress $($ accessed March 2009).

42. Saunders M, Lewis P and Thornhill A. Research methods for business students. 4th ed. London: Prentice Hall, 2007.

43. Datta PP and Roy R. Cost modelling techniques for availability type service support contracts: a literature review and empirical study. CIRP J Manuf Sci Technol 2010; 3: 142-157.

44. Cohen MA. Power by the hour: Can paying only for performance redefine how products are sold and serviced. Available at: https://extranet.cranfield.ac.uk/,DanaInfo $=$ knowledge. wharton.upenn.edu + article.cfm?articleid $=1665$ (2007, accessed November 2007).

45. Kim SH, Cohen MA and Netessine S. Performance contracting in after-sales service supply chains. Manage Sci 2007; 53(12): 1843-1858.

46. Intelligent Manufacturing Systems (IMS). PROMISE product life-cycle management and information tracking using smart embedded systems, http://www.ims.org/ wp-content/uploads/2012/11/2.5.1.3.1-Project-SummaryPROMISE (2012, accessed 10 October 2013).

47. Kirtsis D, Bufardi A and Xirouchakis P. Research issues on product life-cycle management and information tracking using smart embedded system. Adv Eng Inform 2003; 17(3-4): 189-202.

48. Redding LE. An introduction to integrated vehicle health management - a perspective from literature. In: Jennions IK (ed.) Integrated vehicle health management: perspectives on an emerging field. Warrendale, PA: SAE International, 2011, pp.17-26.

49. Cranfield University. Through-life Engineering Services (TLES), http://www.cranfield.ac.uk/about/cranfield/the mes/manufacturing/throughlife-engineering-services.html (2012, accessed 10 October 2013).

50. Gindy N. Sustainable manufacturing, life cycle thinking and the circular economy. Mech Electr Eng Mag 2010; 27(6). Available at: http://en.cnki.com.cn/Article_en/ CJFDTOTAL-JDGC201006003.htm.

51. Lee J, Lapira ER, Yang S, et al. New PLM techniques and trends for asset lifecycle management. In: Roy R, Shehab E, Hockley C, et al. (eds.) Proceedings of the 1st international conference on through-life engineering services: enduring and cost-effective engineering solutions, Shrivenham, 5-6 November 2012.

52. Management of product life-cycle with RFID/USN. In: IMS PROMISE - final project meeting, Athens, Greece. Cincinnati, USA: IMS Centre for Intelligent Maintenance Systems, 2008.

53. Anon. Dynamic decisions in maintenance. In: IMS PROMISE - final project meeting, Athens, Greece, 18 February 2008.

54. Wen-hui Liu, Ping Li and Yu-mei Wen. A structure design for passive wireless SAW pressure sensor. Chin $J$ Sens Actuator 2007; 770-773.

55. Wilson WC, Perey DF, Atkinson GM, et al. Passive wireless SAW sensors for IVHM. In: Proceedings of the IEEE international frequency control symposium, Honolulu, HI, 19-21 May 2008, vol. 1-2, pp.273-277. New York: IEEE.

56. Moseng B. Product lifecycle management and information tracking using smart embedded systems. 2008. Available at: http://www.icbe.ie/Documents/WS4-Moseng-Manufuture2008.pdf (2008, accessed June 2012). 


\section{Appendix I}

\section{Understanding Through-life Engineering Services}

We need your help, please!

We are conducting a survey of manufacturing organisations to further understand cross-sector challenges in maintenance, repair and overhaul (Through-life Engineering Services). We are seeking to improve availability, predictability and reliability of high-value products while reducing service cost. We also wish to understand the level and current state of feedback between engineering services and the design and manufacturing functions.

In order to assist in this understanding this questionnaire is gathering information from manufacturing organisations who through their service operations are improving (or seeking to improve) product design and manufacturing processes so as to increase component life and increase time between services. All responses will be encoded to ensure that the identity of all respondents remains anonymous.

\section{Our commitment to you}

In return for your help, you will receive an executive report detailing the findings of the study, and you will be invited to attend an industry networking event which will take place at Cranfield University in the first half of 2012

\section{What is involved?}

The questionnaire will take no longer than 15 min to complete. The blank text boxes are included in some of the questions for further explanations or comments that you may wish to add. Please complete as many questions as possible and return the questionnaire in the envelope provided. You will find suggested (and hopefully helpful) definitions in the footnotes of a number of pages.

Your response will be treated in the strictest confidence. Responses will not be published unless we have prior consent, and the information provided will be encoded to protect anonymity and will not be shared with any third party. To receive the report and an invitation to the networking and feedback event please provide your contact information and/or business card.

Name:

Company:

Position:

Job Description:

Address:

Telephone number

Email address:

Thank you for your help.

L. E. Redding, EPSRC Centre for Through-life Engineering Services, Building 30 Cranfield Main Campus, Cranfield University, Cranfield, Bedfordshire, MK43 0AL.

Telephone: 01234750111 x2283, email: 1.e.redding@cranfield.ac.uk

\section{Section I: please could you tell us about your company}

This section aims to identify the type of organisation that you are so that effective cross-sector analysis may be undertaken when the data are returned.

Q1.1 Please indicate the sectors in which your business operates.

(Please tick all that apply)

\begin{tabular}{|c|c|}
\hline Aerospace & Marine \\
\hline Agriculture & Mineral Extraction \\
\hline Automotive & Nuclear \\
\hline Civil/Construction & Oil \& Gas \\
\hline Defence & Power \\
\hline Electronics & Security \\
\hline Energy & Telecom \\
\hline Health & Others (Please specify in box below) \\
\hline
\end{tabular}


Q1.2 How would you describe your business?

\begin{tabular}{|l|l|l|l|}
\hline Original Equipment Manufacturer OEM & & Tier 2 Supplier & \\
\hline Tier I Supplier & & Other (Please specify) & \\
\hline
\end{tabular}

Q1.3 Is the business in which you work a.....?

\begin{tabular}{|l|l|l|l|}
\hline A division of a multi-national company & & A public company in its own right & \\
\hline A division of a public company & & Private company & \\
\hline
\end{tabular}

Q1.4 What type of products do you manufacture?

Q1.5 Who are your major customers?

\begin{tabular}{|l|l|l|l|}
\hline Government agencies & & Consumers (B2C) & \\
\hline Private/Public Companies & & Others (Please specify) & \\
\hline
\end{tabular}

Q1.6 Who are your major end users of your products (if different to your customers)?

\begin{tabular}{|l|l|l|l|}
\hline Government agencies & & Consumers (B2C) & \\
\hline Private/Public Companies & & Others (Please specify) & \\
\hline
\end{tabular}

Q1.7 How would you describe your industrial/commercial customers?

\begin{tabular}{|l|l|l|l|}
\hline Government agencies & Predominantly SMEs & \\
\hline Predominantly large organisations & & No Industrial/Commercial Customers & \\
\hline
\end{tabular}

\section{Section 2: please could you tell us about how you deliver your service provision?}

Q2.1 Do you conduct 'in-house' service operations on your manufactured operations?

(Please tick which ever box applies)

Yes

Q2.2 How are these service operations triggered?

Customer/user initiated $\quad \square \quad$ You initiate $\square \quad$ Both

Q2.3 If you trigger maintenance, repair, or overhaul activities then how are these initiated? (Please indicate all that apply - If none apply go to question 2.7)

Time based maintenance systems

Reliability based maintenance systems

Usage based systems

Condition monitoring systems
[Go to Question 2.3]

[Go to Question 2.4]

[Go to Question 2.5]

[Go to Question 2.6] 
Q2.4 Could you tell us a little about how your time based maintenance system is delivered?

Q2.5 Could you tell us a little about how your reliability based maintenance system is delivered?

Q2.6 Could you tell us a little about how your usage based maintenance system is delivered?

Q2.7 Could you tell us about the condition monitoring systems that you use?

Q2.8 When undertaking maintenance, repair and overhaul activities do you record the data/findings that are discovered/observed?

Yes

No

If no then go to Section 3

Q2.9 How do you collect and record MRO data? (Please indicate all that apply)
Paper files
Electronic files
Electronic database
RFID Technology
Remote data collection via
Telecommunications
Satellite Communication
Hand-held portable devices (laptops, scanners, etc)
Q2.10 Once MRO data has been collected what is it used for?
(Please indicate all that apply)
Billing
Spares/inventory acquisition
Time based MRO system
Usage monitoring
Other (Please specify)

Q2.11 Does the data get fed back to the manufacturing function of the OEM?

Yes

No

Q2.12 Does the data get fed back to the design function of the OEM?

Yes

No

Q2.13 Does the data get fed back to YOUR manufacturing function?

Yes

No

Q2.14 Does the data get fed back to YOUR design function?

Yes

No

Q2.15 Can you tell us a little about the nature of the information that is fed back to your design or manufacturing functions and those of the product producer?

We would like to know a little about the state of the data, what it is, how it is presented (i.e. is it performance data, failure categorisation, physical attributes (pressure, temperature, current, power etc)).

Section 3: we would like to understand more about major challenges that you perceive to be overcome within the field of maintenance, repair, and overhaul (MRO) when seeking to inform design and manufacturing

Q3.1 What are the challenges which relate to the capture of MRO data?

(Please indicate the issues within the box provided)

Q3.2 What are the challenges which relate to the structure of MRO data?

(Please indicate the issues within the box provided) 
Q3.3 What are the challenges which relate to the storage of MRO data?

(Please indicate the issues within the box provided)

Q3.4 What are the challenges which relate to the retrieval of MRO data?

(Please indicate the issues within the box provided)

Q3.5 Does your organisation have systems capable of analysing the feedback MRO data?
Yes
No
Go to Q3.7

Q3.6 Please describe the system used for data analysis within your organisation?

(Use box provided)

Q3.7 What are the main technologies that you use for your MRO activities?

Q3.8 What do you perceive to be the technological innovations needed the MRO area in the next 5 years?

Section 4: we would like you to give us insight as to what you perceive to be the major opportunities within maintenance, repair, and overhaul data feedback

Q4.1 Please prioritise in the table below which of the opportunities as identified from the literature that you perceive to be of the greatest importance. (Only rank those you perceive as important. 1 = greatest importance, 18 = least importance)

\begin{tabular}{|c|c|}
\hline Faster identification of failed/degrading component & $\begin{array}{l}\text { The acquisition of real time data from condition } \\
\text { monitoring }\end{array}$ \\
\hline Faster identification of failed/degrading systems & The ability to inform the design process \\
\hline $\begin{array}{l}\text { Reduction in the number of 'No Fault Found' } \\
\text { (NNF) error signals }\end{array}$ & The ability to inform the manufacturing process \\
\hline Greater diagnostic ability & A reduction in Mean Time to Failure \\
\hline Greater prognostic ability & A reduction in $M R O$ lead times \\
\hline Data mining & A more efficient business model \\
\hline $\begin{array}{l}\text { Greater understanding of the user parameters } \\
\text { as applied to the product }\end{array}$ & Protection of revenue streams \\
\hline Increased servitisation & Closer customer integration \\
\hline Product/system learning & Others (please state in box below) \\
\hline
\end{tabular}

Q4.2 Do you have a formal corporate/operating strategy to develop these areas?

Yes

No

Q4.3 Do you have a formal strategy to develop the data feedback from the service function back into either design or the manufacturing function?

Yes

No 


\section{Section 5: future plans}

Q5.1 Do you have plans to move into Through-life Engineering Services?

Yes

No

Q5.2 Do your plans extend to using the data or knowledge obtained through the MRO function to feedback into the Design and/or Manufacturing function?

Yes

No

Q5.3 What are the main reasons for you considering adopting or developing Through-life Engineering Services?

Q5.4 What are the main threats to your moving into Through-life Engineering Services?

Q5.5 What are the main reasons for you NOT having plans to your moving into Through-life Engineering Services?

Q5.6 Would you like to be kept informed as to the activities of the EPSRC Centre for Through-life Engineering Services?

Yes

No

Q5.7 Please feel free to add any additional relevant information that you feel has been omitted from this survey. In addition, please highlight any requests that you would like us to consider or maybe focus upon.

Thank you for completing this survey.

Once the data have been analysed all respondents will receive a copy of the findings by way of an executive report and an invitation to attend Cranfield University to hear the findings presented in a symposium relating to Through-life Engineering Services 
The adoption and use of Through-life Engineering Services within UK Manufacturing Organisations

Redding, Louis E.

Sage

Redding, L. Tiwari, A. Roy, R. Phillips, P. Shaw, A. The adoption and use of Through-life Engineering Services within UK Manufacturing Organisations. Proceedings of the Institution of Mechanical Engineers, Part B: Journal of Engineering Manufacture October 2015, vol.229 no.10 pp1848-1866

http://dx.doi.org/10.1177/0954405414539931

Downloaded from Cranfield Library Services E-Repository 